\title{
Synthesis of Dichloride-diphenylacetonitrile Palladium and Metal-Polymer Composite Based On UHMWPE
}

\author{
A. M. NEMERYUK and M. M LYLINA \\ Federal State Unitary Enterprise "State Research Institute of Chemical Reagents and Pure Chemical \\ Substances"(FSUE "IREA"),107076, Russia, Moscow, Bogorodskiyval, 3. \\ *Correspoding author E-mail: amnamn@mail.ru \\ http://dx.doi.org/10.13005/ojc/320218
}

(Received: December 18, 2015; Accepted: January 25, 2016)

ABSTRACT

New complex of Pd (II) with phenylacetonitrile, suitable for use as a precursor of palladium nanoparticles in the composition of metal-based composite UHMWPE was obtained. The thermodynamic characteristics of metal-polymer composite, found the effect of nanoparticles of palladium in the crystallization processes in UHMWPE and other characteristics of the material.

Keywords:UHMWPE, Metal-polymer Composite, Nanoparticles Pd.

\section{INTRODUCTION}

Metal-polymer composites are of great interest due to the complex of properties that they exhibit. Thus, materials containing ultrafine particles of platinum metals exhibit catalytic activity, containing magnetic particles, such as particles of iron, cobalt, nickel, have the ability to shield electromagnetic radiation in the radio composites containing silver particles exhibit antimicrobial activity. Sometimes introducing into the polymer matrix of metal particles leads to a change of physico-mechanical properties of the composite, increasing durability, reducing the probability of crack formation, the temperature of operation increases.

For composites based on polymer matrix and ultrafine metal particles are often used method of impregnation. When this polymeric substrate saturated with a soluble organic medium a compound which, in the course of further reactions decomposes to release free metal. To this material was treated with ultrasound, UV radiation, is subjected to various chemical influences.

In order to obtain new materials with interesting properties for practical use, the composite materials have been studied, obtained by impregnation on the basis of UHMW polyethylene particles and palladium ${ }^{1}$

Processing UHMWPE products made in different ways, but the main method of processing is hotpressing. Thus UHMWPE powder is exposed to external pressure at temperatures above the melting point of the polymer, typically about $200^{\circ} \mathrm{C}$. 
The temperature rise above this value leads to undesirable thermal degradation processes that result in reduced physical and mechanical characteristics of the material. For use in industrial processes necessary to apply chemical transformations leading to the formation of metal particles in the thermal destruction of the starting compounds, the precursor decomposition temperature of the metal should not substantially exceed $200^{\circ} \mathrm{C}$.

As compounds, palladium metal precursors used quaternary ammonium tetrachloropalladate, palladium carboxylates such as palladium acetate, complexes of Pd (II), formed nitriles, isonitriles and alkenes. $\ln ^{2}$ describes the preparation of metalpolymer composite by impregnating polystyrene various palladium complex compound wherein ligands are used as aliphatic and aromatic nitriles, and alkene nitrile blend. The authors found a correlation between the nature and character of the complex used in the polymer matrix particles of palladium. It was shown that the higher the lipophilicity of compounds of palladium, the greater the amount of metal possible to introduce into the polymer matrix and for the most lipophilic compounds is not observed the formation of particulate metal, and continuous layers covering the internal void in the structure of the polymer matrix ${ }^{3,6}$.

Using $(\mathrm{PhCN})_{2} \mathrm{PdCl}_{2}$ and $\left(\mathrm{CH}_{3} \mathrm{CN}\right)_{2} \mathrm{PdCl}_{2}$ not lead to optimal results, as lipophilicity acetonitrile complex appeared excessive and benzonitrile complex in sufficient ${ }^{6-8}$. Based on these data, it was assumed that an optimum combination of properties,

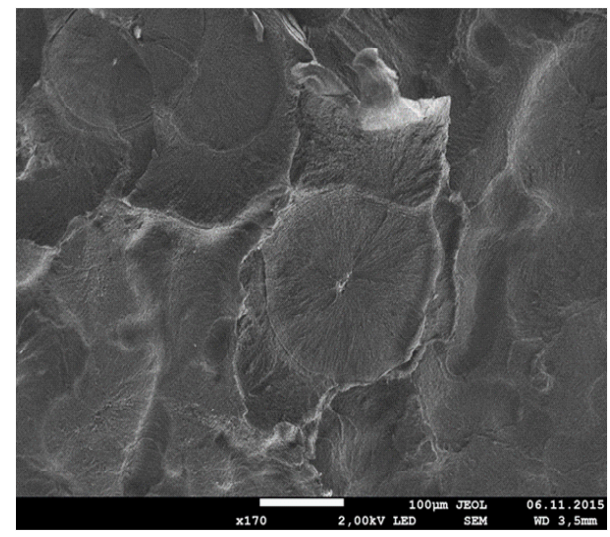

Fig. 1: the image of the internal structure of the composite material on the basis of UHMWPE particles containing $\mathrm{Pd}$ including lipophilicity and the decomposition temperature is necessary to use a palladium complex, wherein the ligand is used as the fatty-aromatic nitrile having in the molecule both an aromatic moiety and aliphatic. As such a compound, we used a complex of palladium dichloride and phenylacetonitrile.

\section{METHODS}

Phenylacetonitrile, palladium chloride, benzene, hexane, were purchased from SigmaAldrich, benzene and hexane were dehydrated by prolonged boiling with phosphorus oxide and subsequent distillation, phenylacetonitrile was distilled in vacuo. UHMWPE Ticona GUR 4113.

\section{Dichloride di(phenylacetonitrile) palladium}

$3 \mathrm{~g}$ of palladium dichloride was added to $20 \mathrm{~g}$ of phenylacetonitrile and stirred for 1 hour at room temperature. The mixture was then heated to $80^{\circ} \mathrm{C}$ and stirred for 6 hours. After cooling the reaction mixture to room temperature, the solution was filtered and to the filtrate was added $30 \mathrm{ml}$ of a benzene-hexane 1: 1. Trituration crystallization, dichloride di(phenylacetonitrile) palladium isolated as yellow crystals. After standing overnight at $0^{\circ} \mathrm{C}$, crystals were collected by filtration and recrystallized from benzene-hexane 1: 1.2.78 $\mathrm{g}$ of the product obtained yellow crystals.

Calculated C 46,68H3,42 N6,80 Cl17,22 Pd 25,85, found C46,70 H3,39 N6,75 Cl17,46 Pd 25,7 decomposes at $\mathrm{T}>200^{\circ} \mathrm{C}$.

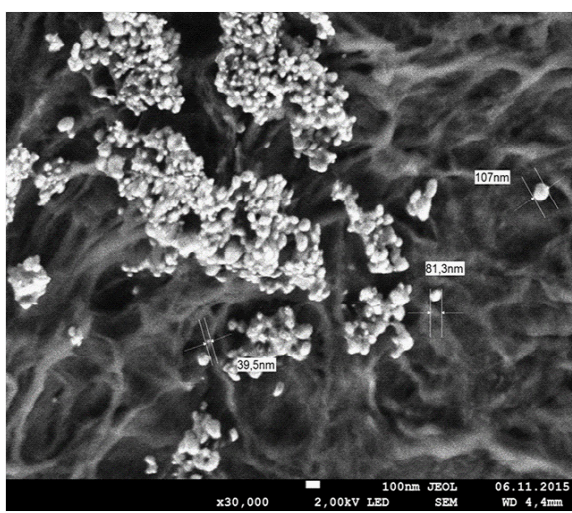

Fig. 2: Assemblies of nanoparticlesPd and individual particles in a polymer matrix UHMWPE 
Impregnation dichloride di(phenylacetonitrile) palladium UHMWPE

$138 \mathrm{~g}$ of UHMWPE powder with a particle size of 50-200 microns was mixed with $200 \mathrm{ml}$ of a solution of $1 \mathrm{~g}$ dichloride di(phenylacetonitrile) palladium in benzene and stirred at $75^{\circ} \mathrm{C}$ for 12 hours. UHMWPE is filtered off and washed repeatedly with benzene. After removal of solvent residues in vacuum to yield a powder of UHMWPE containing $0.4-0.6 \% \mathrm{Pd}$.
Hot pressing of composite based on UHMWPE

UHMWPE powder containing $0.5 \%$ dichloride di(phenylacetonitrile) palladium incubated at $110^{\circ} \mathrm{C}$ for 40 minutes. Then pressed for $4 \mathrm{hrs}$ at a pressure of $10 \mathrm{MPa}$ and a temperature $(185-210)^{\circ} \mathrm{C}$. The samples were then cooled to room temperature at a rate of $3-4^{\circ} \mathrm{C} /$ minute.

\section{RESULTS AND DISCUSSION}

The resulting samples were examined by scanning electron microscopy, and IR spectroscopy,

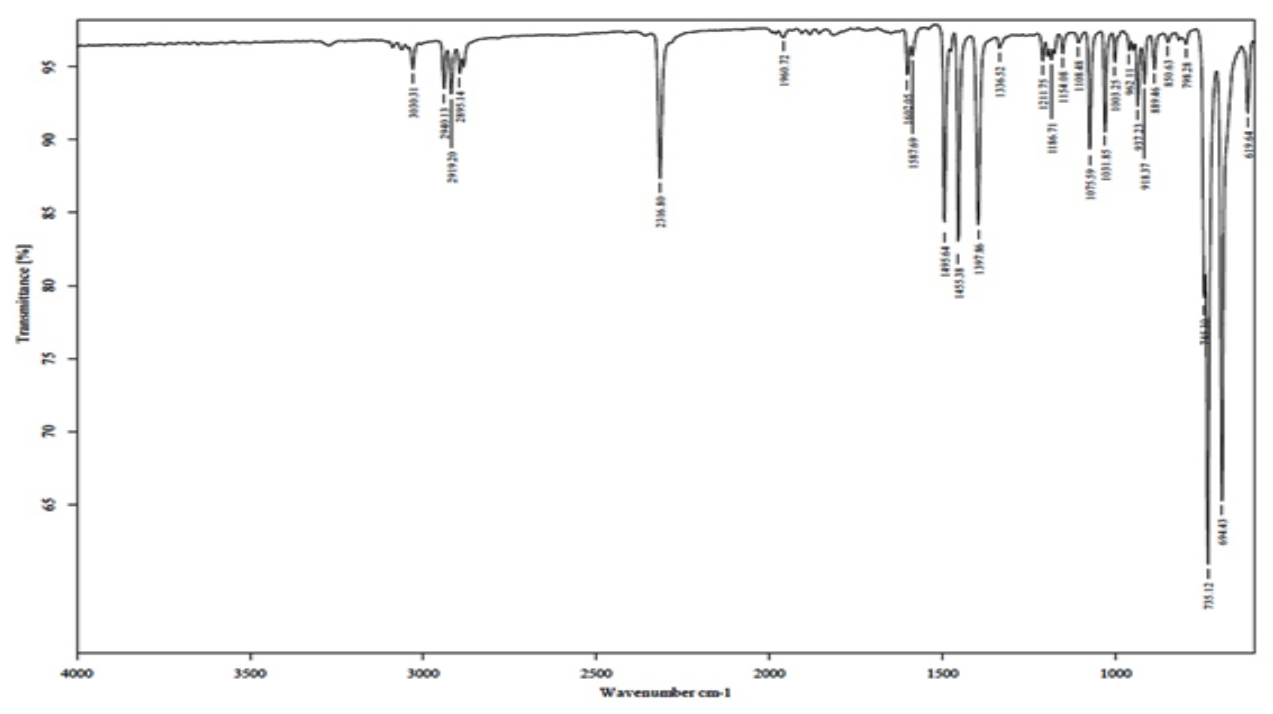

Fig. 3: IR absorption spectrum of the dichloride di(phenylacetonitrile) palladium

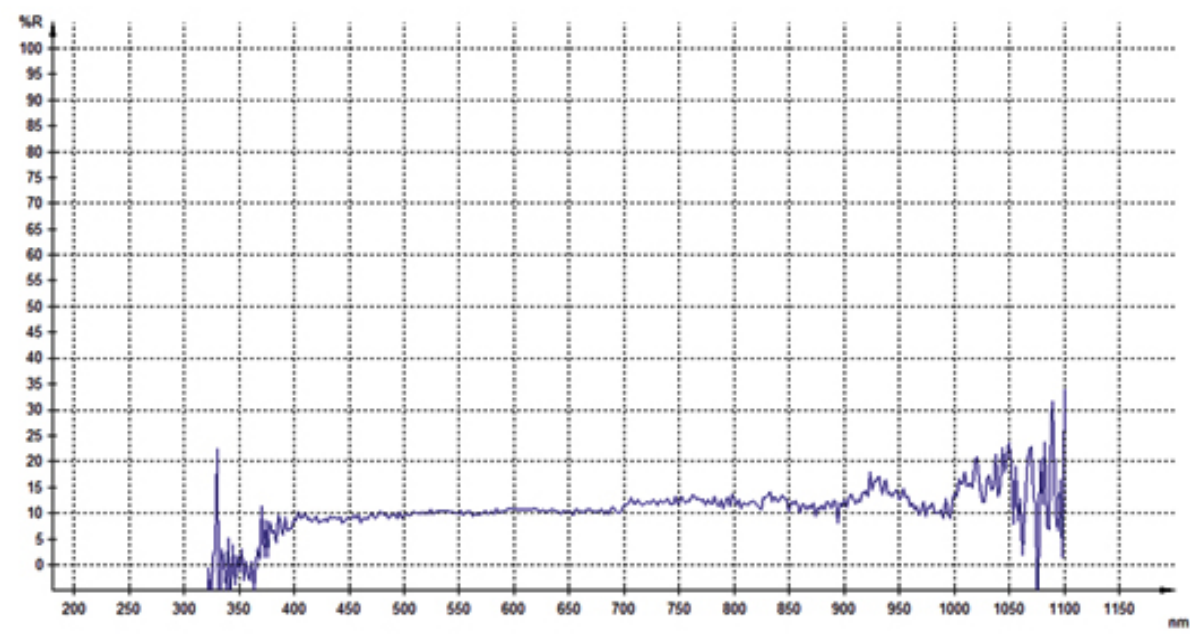

Fig. 4: IR reflection spectrum for a sample of UHMWPE containing ultrafine Pd particles 


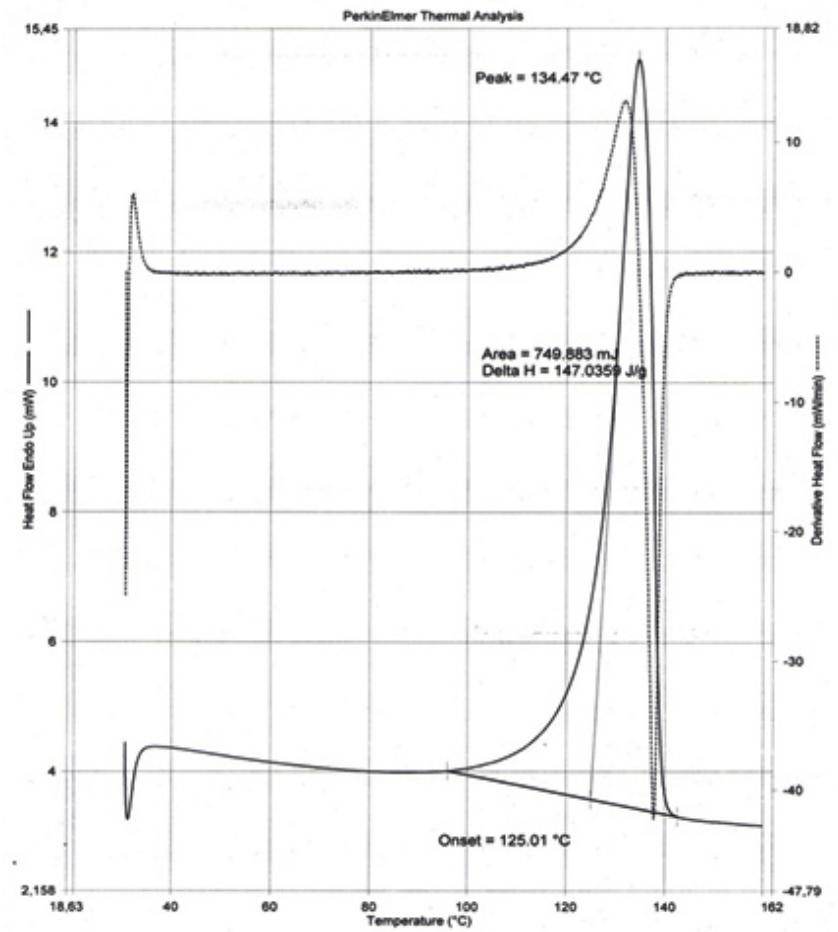

Fig. 5: heat flow versus temperature for UHMWPE containing ultrafine particles of Pd

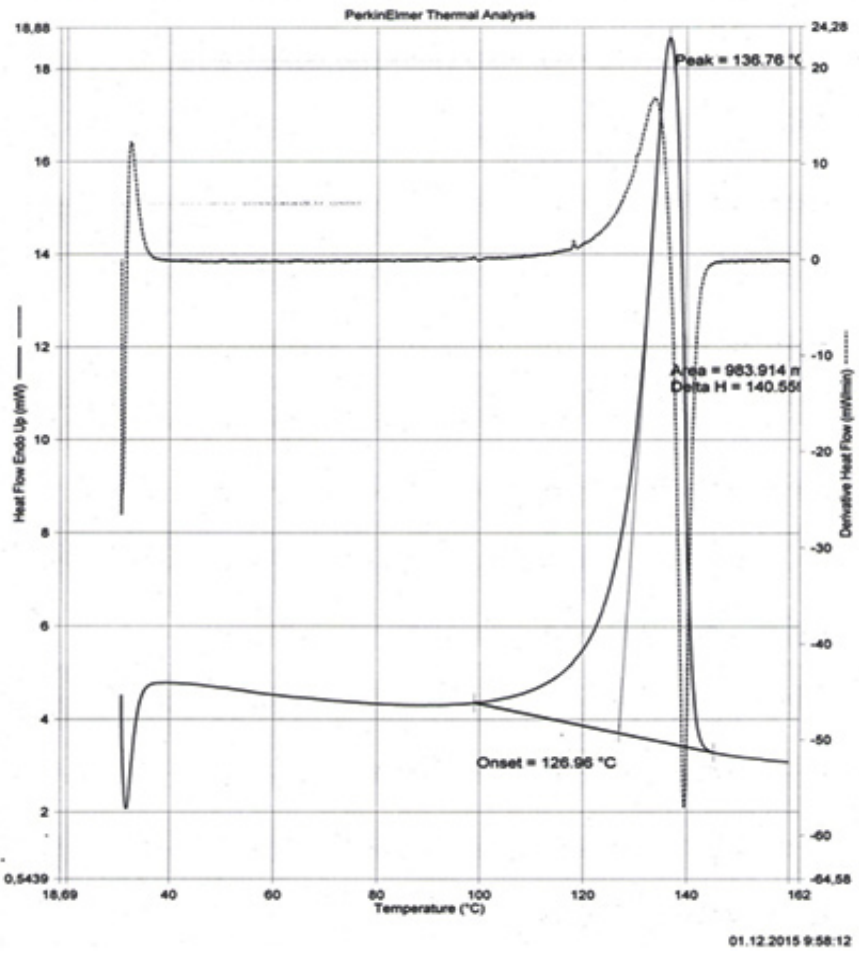

Fig. 6: heat flow versus temperature for the starting UHMWPE 
differential scanning calorimetry. To investigate the internal structure of the composites based on UHMWPE samples were cooled with liquid nitrogen and are made to prevent faults surface structure changes during sectioning. Images obtained by SEM are shown in Figure 1 and 2.

IR absorption spectrum was recorded for dichloride di(phenylacetonitrile) palladium, Figure 3. IR reflection spectra were obtained using a device based on the FT-IR spectrometer VERTEX 70 with the prefix ATR (ZnSe) Figure 4.

To determine the thermodynamic characteristics of the materials obtained were investigated by DSC, it was defined as the melting start temperature and the melting point of the composite, and the starting UHMWPE. It has been found that the introduction of palladium ultrafine particles leads to a slight decrease in the melting temperature (Figure 5 and 6).

The results obtained in the course of research data indicate that dichloride di(phenylacetonitrile) palladium compound is suitable for use as a precursor of palladium nanoparticles to create metal-polymer composites based on polymers of low polarity, for example, UHMWPE. Sufficiently thermally stable substance and, unlike palladium carboxylates, it decomposes with the release of metal only at temperatures exceeding the melting temperature of the UHMWPE. According to the obtained SEM for faults material made after liquid nitrogen cooling, the metallic particles are the centers of the formation of spherulites regions of crystallinity in the polymer matrix UHMWPE. The size of the particles produced in this Pd ranging from 40 to $100 \mathrm{~nm}$ in the central regions of the spherulites also detected aggregates of nanoparticles. This confirms the assumption that formed during the thermal degradation of the polymer matrix palladium nanoparticles are centers of crystallization of UHMWPE, which occurs upon cooling of the material below its melting point. DSC showed a slight decrease in the melting point, which may indicate the influence of the introduction of the composite metal particles on the crystallinity of the polymer. On the other hand dichloride di(phenylacetonitrile) palladium has significant lipophilicity, which allows the impregnation of the polymer matrix to create a precursor concentration sufficient to provide metal-polymer composites containing up to $0.4-0.6 \%$

\section{CONCLUSION}

An integrated connection dichloride di(phenylacetonitrile) palladium. It has been found that the interaction with the fine powder of UHMWPE in a medium boiling benzene impregnating polymer complex occurs. When hotpressing impregnated powder compact obtained samples of metal-polymer composite containing $0.4-0.6 \% \mathrm{Pd}$. Study of the composites SEM confirms the presence of metal in the composite particles of spherical shape with a size of $40-100 \mathrm{~nm}$. The particles of palladium metal formed by heating in a polymer matrix, are the centers of crystallization of UHMWPE that influences packing of macromolecules in supramolecular aggregates.

\section{ACKNOWLEDGEMENTS}

Applied researches are carried out with financial support of the state by the Russia Ministry of Education and Science under Grant Agreement 1 14.576.21.0004 of June 17, 2014. (Unique identifier for Applied Scientific Researches (project) RFMEFI57614X0004).

\section{REFERENCES}

1. Sing K. S. W., Everett D. H., Haul R. A. W., Moscou L.,Pierotti R. A., Rouquerol J.,Siemieniewska T. In Handbook of Heterogeneous Catalysis. Wiley-VCH Verlag GmbH\&Co, Weinheim 2008.

2. Tsvetkova I. B., Matveeva V. G., Doluda V. Y.,Bykov A. V., Sidorov A.I.,. Schennikov S V, Sulman M. G., Valetsky P. M.,Stein B. D.,
Chen C-H.,Sulmanb E. M. and Bronstein L. M. J. Mater. Chem, 2012, 22, 6441-6448

3. Lamblin M., Nassar-Hardy L., Hierso J.C., Fouquet E., Felpin F.X.Adv. Synth. Catal.,2010, 352, 33

4. Lu J., Toy P.H. Chem. Rev.,2009, 109, 815

5. McNamara C.A., King F., Bradley M. Tetrahedron Lett.,2004, 45, 8239 
6. Elson K.E., Jenkins I.D., Loughlin W.A. Tetrahedron Lett.,2004,45, 2491

7. Mansour A., Portnoy M., MolJ. Catal. A:
Chem., 2006,250, 40

8. Bergbreiter D.E., Kippenberger A.M., Tao G. Chem. Commun.,2002, 18, 2158 